\title{
Reproductive Behaviour in Pakistan: Insights from the Population, Labour Force, and Migration Survey 1979-80
}

\section{ZEBA A. SATHAR and MOHAMMAD IRFAN*}

\section{INTRODUCTION}

Pakistan, with a population of 83 million at the 1981 census, ranks as the ninth largest nation in the world. Owing to the persistently high levels of fertility and the concomitant relatively low levels of mortality, Pakistan's population has registered an annual growth rate of about 3 percent over the last two decades. This high growth rate poses a problem to all those concerned with the effects of rapid population growth in the face of limited global resources. Although a slight decline in Pakistan's fertility had been recorded in 1975 , it was considered to be of little significance and a phenomenon too recent to influence population growth [1]. A 12-percent decline in fertility during the 1970-75 period, as suggested by the Pakistan Fertility Survey (PFS) data, however, generated hopes that Pakistan may well be entering into an era of declining fertility. There is an urgent need to investigate whether this decline was real and whether it continued in the late Seventies. Answers to these queries are of paramount importance both for population-related research and for policy formulation. In this context, the data collected for Studies in Population, Labour Force, and Migration (PLM) - a PIDE/ILO-UNFPA project [5] - may be extremely useful.

The PLM project was multipurpose in character, with the major objective of identifying the set of factors bearing upon the productive and reproductive decisions of the household. In order to operationalize the objectives a set of four questionnaires dealing with the I abour Force, Household Income and Expenditure, Migration and Fertility was administered to a nationally representative sample of 11,000 households ${ }^{1}$ in July-December 1979 . The data thus collected not only present a unique opportunity to understand the nature of relationships between a variety of

*Research Demographer and Chief of Research, respectively, at the Pakistan Institute of Development Economics, Islamabad (Pakistan).

${ }^{1}$ For details of the PLM Survey, see [5]. 
factors and fertility but also permit a comparison of fertility levels, trends and differentials with the findings of earlier surveys, such as the Pakistan Fertility Survey (PFS).

\section{CHANGES IN FERTILITY}

As mentioned in the introduction, there was a hint in the PFS data of the onset of a fertility decline in Pakistan. A comparison of the PGE (1963-65) LR-CD average with the 1970-75 estimate of total fertility rate is suggestive of a decline in the total fertility rate from 7.0 children to 6.3 children per woman. Similarly, the PFS data on reproductive histories also indicate that there had been a decline in fertility from 6.5 children per woman in the $1965-70$ period to 6.3 children per woman in the 1970-75 period. While it could have been argued that the methods of data collection of the PGE and PFS were sufficiently dissimilar and a fertility decline between the two surveys can be suspected, the trend reflected by the PFS pregnancy-history data was regarded to be on firmer ground. It was, therefore, concluded that a 12-percent decline in fertility had occurred in the 1970-75 period $[1]$.

A closer scrutiny of the PLM data, a product of an identical questionnaire and the same data collection procedures as those of PFS (1975), fails to substantiate the above findings. In fact, for the very period (1970-75) for which a fertility decline was recorded by PFS, the PLM data tend to suggest a rise in fertility. In addition, the PLM data indicate a slight rise in TFR from 6.3 in 1970-75 (using PFS data) to 6.5 in $1975-79$ (using PLM data). What is quite quizzical, however, is the fact that the PLM data like the PFS data reflect a decline in TFR for the last period before the survey - from 6.9 in $1970-75$ to 6.5 in 1975-79. There appear to be problems involved in computation of the fertility levels for the five years preceding the survey. In a companion exercise, the fertility decline estimated from either survey for the 6-8 year period preceding each survey by the "Own-Children Method" is regarded as spurious. In fact, the two trend lines are found to be very similar, differing primarily by a time displacement of four years, equal to the length of the inter-survey period [11]. Since the same pattern is found in the estimation of fertility from maternity histories and household data (used to arrive at "OwnChildren" estimates) it leads us to conjecture that these declines in the tail ends of the two surveys are probably due to age mis-reporting of younger children, especially those aged $0-4$ years. However, until there is a meticulous investigation to establish whether the changes are real or an artefact it appears safe to presume that there was no perceptible decline in Pakistan's overall fertility levels in the 1970s.

A major change has occurred in reproduction-related behaviour in the form of a rise in the age at marriage of both men and women in Pakistan. In fact a very important change in Pakistan's demographic situation in the last decade seems to be the continuous rise in age at marriage. The Family Laws Ordinance, promulgated in 1961 , legalized the minimum age at marriage at 16 years for females and 18 years for males. This may have had some impact on reporting of ages at marriage as in many cases those under age may have reported higher ages to satisfy the legal requirement, and may explain the convergence in age at marriage around that figure of 16 for 1961 . However, since then the subsequent censuses of 1972 and 1981 have confirmed that the rising trend continues and the singulate mean age at marriage reported for males and females for 1981 are 25.4 and 20.8 years respectively. Data from cross-sectional surveys such as the National Impact Survey, the Pakistan Fertility Survey and the PLM tend to recount the same story, though they are subject to some biases as their samples were confined to ever-married women, and particularly at younger ages selectivity leads to a downward bias in the estimates of mean age at marriage [9].

These surveys do enable us to assess the differentials in age at marriage, and the PLM survey shows that age at marriage is higher in urban areas and in the more prosperous provinces of the Punjab and Sind. A strong positive relationship between years of schooling of a woman and her age at marriage was also found. In particular, primary or higher schooling was associated with a much higher age at marriage. Husband's education was also positively related to woman's age at marriage as was his occupational status. Quite probably, husband's education and profession and wife's education are bound to be closely correlated and representative of a selective elite [6]. Thus, although the more educated women and those residing in urban areas and with professional husbands are displaying more advanced stages of changes in nuptiality pattern, the census figures reflect fairly large-scale, if not drastic, changes in marriage behaviour across the country [9].

Women who marry at later ages seem to have a rapid pace of child-bearing in the earlier years of marriage. A more complete study of birth-spacing patterns from the PLM Survey is urgently required because a shorter spacing between births may be under way. There are, firstly, hints of possible shortening of the first birth-interval as age at marriage is rising, and, secondly, a shorter length of breast-feeding is being reported in 1979 as compared to that in 1975 . The mean length of the interval between marriage and first birth follows a U-shaped curve; it is longest for those who marry either at early ages or at relatively older ages. For those married at the age of 18-19 years (which is where the mean age at marriage for Pakistan now lies), the first birth-interval is shortest, but still almost two years long. Compared with those in other societies, this first birth-interval is fairly long in Pakistan and it has been suggested that it may be either due to reporting errors or due to a gap between marriage ceremony and actual cohabitation, which may be diminishing in contemporary Pakistan as women are marrying at older ages. 
The second and more important indicator of shortening in birth-spacing in Pakistan is the decline in the length of breast-feeding in the PLM as compared with that in 1975. The length and intensity of breast-feeding in a largely natural-fertility population like Pakistan are major determinants of intervals between consecutive births, as they are directly related to the period of lactational infecundability. Especially in the absence of significant levels of contraceptive use, breast-feeding is perhaps the most important proximate determinant of fertility. A brief comparison of the magnitude and differentials in breast-feeding between the PFS and PLM Survey shows that although there has been no major shift in the pattern of differentials in breast-feeding, the mean length of breast-feeding is reported to be a couple of months shorter in the PLM Survey than in the PFS, for almost all groups [8].

The length of breast-feeding is an improtant determinant of fertility levels in a society where little or no control is being exercised over reproduction. However, in the past, declines in breast-feeding associated with modernization, or perhaps more aptly Westernization, have been followed by an increased use of contraceptive methods for spacing. This is not yet the case in Pakistan. In fact, according to the PLM Survey, knowledge and, more crucially, the use of contraception declined in the latter half of the Seventies, the more crucial factor perhaps being that at the time of the PLM Survey the fervour of institutionalizing Islamization may have had an inhibiting effect on responses about knowledge and use of contraceptives. Knowledge of most methods has recorded a decline since the PFS in 1975 except the knowledge of condoms which has remained the same while knowledge of female sterilization has actually registered a rise since 1975 . However, levels of contraceptive knowledge were higher amongst urban women, women older than 25 , those women who said that they wanted no more children and those who stated that they had exceeded their ideal family size. Education of wife, not surprisingly, had the strongest positive correlation with contraceptive knowledge [13].

Levels of contraceptive use have registered a decline since 1975. A decline from 10.5 percent in 1975 to 4.9 percent in 1979 has been registered in the current use of contraception. It is interesting to note that the current use of efficient methods did not vary much across the PFS and the PLM Survey which suggests that although the use of traditional methods was lower in the PLM Survey, users of efficient methods continued to seek out these methods. Urban-rural differentials in ever- and current-use persisted in 1979 with much higher use in the urban areas. Once again, wife's education bore the strongest relationship with contraceptive use, which was particularly high amongst those women who had acquired primary or higher education [13].

Though infant mortality and fertility are known to be closely intertwined, their impact on each other is hard to establish definitively. It is worthy of noting that although infant mortality experienced declines during the earlier half of the century, it has stabilized at quite high levels in recent decades. It claims a significant portion of mortality at its high level of between 125 and 140 deaths per 1000 births. The PFS established an infant mortality rate of 140 per 1000 for the 1970-75 period and the PLM Survey shows a rate of about 125 per 1000 for the 1975-79 period. The discrepancy shown by these two figures could possibly be a result of the compositional differences in the samples of the two surveys. ${ }^{2}$

Perhaps the most important findings from the PLM-type surveys are the differentials which reflect the varied health and nutritional conditions experienced by different segments of the population. For instance, the rural population experiences an infant mortality rate about 25 percent higher than that experienced by the urban population. Similar levels of differences are found between infant mortality rates of educated and uneducated mothers. In addition to the usual socio-economic variables, such as education and residence, the PLM Survey collected unique information on land tenure, and it was found that in the rural areas about 17 percent of the children born to those working as landless agricultural labourers died before the age of one. The comparable figure for all children was 13 percent and for owner-cultivators with cropped areas of 100 acres and above it was 6 percent. The information on income collected in the PLM Survey also presents a unique opportunity to investigate its relationship with infant mortality, which had been an area almost wholly unexplored. The relationship is strikingly negative amongst literate fathers in the urban areas, where 7 percent of children whose fathers were literate and had an income of Rs. 2800 and above died before age one whereas the corresponding figure for literate fathers with income of Rs. 560 or less is twice as high. The relationship, although negative, amongst illiterate fathers was found to be less strong.

Given the limitations of the data, it may tentatively be concluded that reproductive behaviour in Pakistan is undergoing changes which may have contradictory influences on fertility. Hence, no unidirectional trend has emerged thus far. Recent studies elsewhere have shown that the proximate determinants can often have conflicting effects on fertility. In Pakistan, we may be faced with a similar situation wherein age at marriage has risen resulting in lower proportions of those married and, therefore, lower fertility at younger ages. This may be being counteracted by a shortening of the length of breast-feeding unaccompanied by rises in the use of contraception and thereby producing a fertility-enhancing effect. Infant mortality is still alarmingly high and may well be a major cause of continuing high fertility as families desirous of ensuring survival of a certain number of children continue to compensate for their infants' loss through death.

\footnotetext{
births. ${ }^{2}$ The available data sources yield infant mortality rates ranging from 80 to 140 per 1000

${ }^{2}$ The available data sources yield infant mortality rates ranging from 80 to 140 per 1000
births.
} 


\section{CORRELATES OF REPRODUCTIVE BEHAVIOUR}

Like most studies of fertility determinants using cross-sectional data we report findings from an exercise using multivariate techniques to assess discriminatory characteristics which are statistically significant in terms of reproductive behaviour [7].

The multivariate analysis adopted to assess differentials in reproductive behaviour is based on children ever born (CEB) as the measure of fertility performance of each individual woman. In order to reckon with the differences in environment which define the opportunities and constraints for households, the sample was divided into four subgroups - rural non-farm, rural farm, urban metropolitan and urban non-metropolitan. The details of the regression exercise and the rationalization of the inclusion of variables in the model are available in another publication; see [7]. We are concentrating here on just highlighting the points of interest to be drawn from this more detailed exercise.

First of all, the results show that the variables included in the analysis vary in their significance in the different sub-populations, thus confirming the varying circumstances which must apply there. The differences across the four subgroups are to some extent self-evident. Most of the population (about 75 percent) resides in rural areas and the majority is engaged in farming. Thus the rural-farm group constitutes the major subgroup, followed by the rural non-farm population. In the urban areas, it is worth differentiating between those who live in metropolitan areas, i.e. cities with populations of more than 4 lakhs $(400,000)$ persons, and those living in smaller urban localities, as socio-economic conditions and, therefore, reproductive behaviour may vary across this demarcation line.

In discussing the results of these regressions, it should be eriphasized that some variables are obviously more critical in explaining variations in reproductive behaviour than others. For instance, women's work participation has been much discussed in the literature on women's status, and its importance for fertility behaviour can hardly be emphasized. Its correlation with fertility, though generally negative, was of no significance to reproductive behaviour in any sub-population. This lack of association finds its explanation in the absence of the role incompatibility and in problems associated with measurement of labour force. Inadequate concepts of work fail to include all working females in the labour force, yielding a very low fraction (9 percent) of females as working [7]. The statistical distinction between working and non-working females is, therefore, of little importance.

Women's educational attainment is perhaps an even more extensively discussed topic than women's work in the literature on correlates of fertility [4]. Educational attainment is not only believed to have a direct impact on a woman's life through increased knowledge and use of contraception, in postponing her marriage etc., but is also correlated highly with her socio-economic status measures which may be influencing her reproductive behaviour. School attendance in a society like Pakistan, where literacy levels especially of females are appallingly low, leads to the selection of women from a very elite group. Higher levels of educational attainment (i.e. of middle school and above) are found to be strongly related inversely to fertility in urban metropolitan and non-metropolitan areas. However, when the household income measure is also introduced into the regression, then female education in urban non-metropolitan areas becomes non-significant, though its coefficient still remains negative. The educational attainment variable maintains its statistical significance in the urban metropolitan areas even though the size of the coefficient diminishes with the introduction of the measure of household income. Female education hardly has any independent effect on reproductive behaviour in rural areas, a finding somewhat contradictory to that of the PFS where the relationship between education and fertility was stronger in rural areas than in urban areas [12] It is interesting to find, as was expected on a priori argument, that income and educational attainment do bear a strong correlation with each other as their joint inclusion, at least in the urban areas, does change the results.

Before proceeding to discuss the importance of other variables pertaining mostly to socio-economic and residential characteristics of the husband or household, let us briefly confirm the impact of the demographic variables included in the regression analysis. They are age, age at marriage, contraceptive use and breast-feeding. Age has a significant and positive relationship with fertility whereas age at marriage is negatively and significantly associated with the number of children ever born. The two associations are unvarying across all the four subgroups of the population. Breast-feeding has been incorporated into the analysis as two binary variables, one which measures duration of breast-feeding between six and twelve months and the other which measures durations of breast-feeding of more than 12 months. Interestingly, the findings show that in comparison to those women who did not breast-feed or breast-fed for less than six months, the fertility of those who breastfeed for 6-12 months was higher. The longer period of breast-feeding, of more than 12 months, bore the expected negative association with fertility though this is not statistically significant except in the case of high-parity females. Those women who did not breast-feed at all or breast-fed for less than 6 months must certainly represent a very select group who are most likely to be either very educated or rich (who totally substitute breast-feeding for baby foods and milk) or physiologically so impaired as to be unable to breast-feed. This may be a major reason for relatively higher fertility associated with women breast-feeding for 6-12 months, a relatively short period compared with national averages of $15-16$ months. However, the methodological problems involved, along with possible measurement errors in estimating length of breast-feeding, do not enable us to be very conclusive about the role of breast-feeding in fertility, at least as included in the regression analysis. As 
for contraceptive use, a significant and positive association was found with fertility for all the four subgroups. This reflects the commonly found strong association of contraceptive use only amongst higher-parity women in societies like Pakistan where contraceptive adoption is more acceptable once a certain family size has been attained.

We turn now to look at characteristics associated with a woman's husband or the household to which she belongs which may differentiate her fertility achievements. Nuclear family households are found to be associated with higher fertility in all the four subgroups. However, this variable may be vulnerable to definitions of what constitutes a household. Reasons for such a finding may be greater privacy and therefore sexual freedom and a greater desire to have many children to increase family size when a couple breaks away from the paternal home.

Both variables, which measure levels of educational attainment of husbands, have a positive but non-significant coefficient in urban metropolitan areas. However, in urban non-metropolitan areas the highest level of husband's education does acquire a negative, though non-significant, coefficient. In rural farm households as well, when household income and assets like land are included, the very highest level of educational attainment is associated with lower family size. This once again brings out the fact that husband's education, most probably even more so than wife's education, is strongly tied up with other measures of socio-economic status such as income and land ownership. By itself, husband's educational level seems to be of little importance in terms of reproductive behaviour and, if anything, it seems to have a curvilinear relationship with fertility (i.e. reverse U-shaped). This, once again, is along the lines of the findings of the PFS [3].

This latter observation, in fact, brings out the unique advantage of the PLM Survey over the other data sets used to study fertility on a national level, because of the availability of direct measures of income, land and other ownership. The relationship between household income and fertility levels emerges as statistically significant in both urban and rural areas. However, the relationship is non-linear, with income having a positive coefficient, while the squared term of income has a negative but significant coefficient. Thus, up to a certain level of income, there is a positive correlation of income with fertility whereas the relationship reverses after a certain income threshold has been reached. Although this is a novel and useful finding in the case of Pakistan, we hesitate to lay too much store on it due to the known problems of measuring income even in developed societies, leave alone developing societies, where a large margin of error can be expected.

Ownership of land, incorporated in the regressions run on the rural farm population areas, showed up as positively related to fertility up to a threshold level of 20 acres, after which it becomes statistically non-significant and, in most cases, negatively associated with fertility. In a preliminary exercise it was found that tenurial status, which a priori would have been expected to be associated with fertility is in fact not critical, i.e. landowners and share-croppers did not differ in their reproductive behaviour once size of land was included in the equation.

A significant negative association was also found in rural farm households between ownership of a tractor and fertility levels. Since income and land-ownership were incorporated in the regression, this finding seems to suggest that the existence of a tractor may reduce the agriculturist's demand for labour and consequently for children. Also, those who purchase tractors may be speculated to be more innovative or more ready to try out new modes of production and, therefore, more willing to exercise control over their reproductive behaviour also. Ownership of cosumer durables, on the other hand, was non-significant except in urban metropoli$\tan$ areas where consumer durables are found to substitute for children to some extent.

A woman's aspirations and desires regarding her children are bound to influence the number of children she eventually has. For instance, if she wants to put them through school she will probably have fewer children as she plans to invest in them more. It was found, as per expectations, that the association between child schooling and fertility was negative, though statistically significant only in urban metropolitan areas. Thus, in the rural areas where more schools are likely to be publicly financed than in urban areas (where private schools are more prevalent), child schooling is less likely to enter into fertility decisions. Preference for sons, as measured by the proportions of daughters amongst living children, shows up in both rural and urban areas, but seems to have some interactive effect with land and breastfeeding. Also, mortality of children, as measured by the inverse of the child survival ratio, was found to be positively correlated with fertility. This finding, however, is not very revealing because the causal mechanism may be working both ways, with fertility influencing mortality and vice versa.

Since the regressions have been run separately for urban metropolitan, urban non-metropolitan, rural non-farm and rural farm households, we do not incorporate them as separate variables. However, province of residence emerged as significant in rural farm and non-farm areas, indicating that there are significant differentials between the rural areas of the four provinces. This is reflective of differences across them in development and cultural habits. Farm hosueholds in Baluchistan seem to have the lowest fertility levels; the fertility of non-farm rural areas in the NWFP and Baluchistan are comparable. Rural areas of both these provinces are roughly similar in development and in culture. The rural areas of the Punjab and Sind are better off in terms of income than corresponding areas in the NWFP, and fertility
levels are generally lower there. 
Last of all, the PLM Survey offered an opportunity to determine whether the presence of certain institutions $s^{3}$ in a rural community affected reproductive behaviour of women residing there, that is independently of all other factors discussed hitherto. The results were disappointing-neither educational institutions nor health facilities made any impact in the rural farm areas. The coefficient of the existence of a hospital or dispensary, however, had a positive sign in the rural areas but was significant statistically only in some rural non-farm households. This positive association with fertility may be reflective of lower losses during pregnancy and lower maternal mortality because of better health care due to availability of some medical facilities. In general, it seems that decisions regarding reproductive behaviour, at least in rural areas, are influenced by characteristics of the household or of the individual husband or wife and are hardly amenable to community-level policy interventions. This once again reflects the findings of the PFS. However it was argued there that perhaps community variables were not measured adequately $[10]$.

\section{CONCLUDING REMARKS}

Results from the PLM Survey seem to suggest that fertility levels did not change in the Seventies. However, reproductive behaviour in terms of birth spacing, breast-feeding and age at marriage does portray some mixed trends which have yet to manifest themselves in overall fertility changes at the national level. Shortening of birth spacing by women who marry at ages higher than 18 and curtailment of the lactation period over time may lead to at least temporary increases in marital fertility, given the strikingly low figures of contraceptive use found in the PLM Survey. However, marital fertility rates show no real increase and the case is strengthened to assert that contraceptive use must have been severely under-reported in the PLM Survey in 1979 , a time when family planning was not being officially promoted and the fervour of Islamization discouraged admission by respondents. Increases in the age at marriage and declines in breast-feeding are generally concomitants of fertility transition, but if they are unaccompanied by increases in contraceptive use (as seems to be the case in Pakistan) they present a rather depressing picture of fertility levels, at least for the near future.

Overall, fairly homogeneous reproductive behaviour seems to prevail across Pakistan. Reproductive behaviour differentials appear to affect only elite members of the population. Thus women educated beyond primary school, households with high incomes and landed rural aristocracy owning a tractor-all very select groupshave lower fertility. Marginal betterment of socio-economic conditions, as in the

${ }^{3}$ These variables were not pertinent to urban areas as almost all of them would have access to these institutions. case of women with husbands who acquired schooling up to the primary level, and families where the household income was in the middle ranges of income distribution was associated with rises in fertility. The small size of the groups of those having significantly small family sizes is confirmed by the fact that overall reproductive behaviour in Pakistan remains relatively static. Only major changes in the socioeconomic structure resulting in the changes of the perceptions and expectations of parents regarding old-age security, schooling of children and social mobility can bring about significant declines in fertility in Pakistan.

\section{REFERENCES}

1. Alam, I. "Fertility Levels and Trends". In Iqbal Alam and Betzy Dinesen (eds.), Fertility in Pakistan: A Review of Findings from the Pakistan Fertility Survey. Voorburg, Netherlands: International Statistical Institute. 1984.

2. Alam, I., et al. "Fertility Levels, Trends and Differentials in Pakistan. Evidence from the Population, Labour Force and Migration Survey 1979-80". Islamabad: Pakistan Institute of Development Economics. 1983. (Studies in Population, Labour Force and Migration Project; Report No. 1)

3. Casterline, J. "Fertility Differentials in Pakistan". In Iqbal Alam and Betzy Dinesen (eds.), Fertility in Pakistan: A Review of Findings from the Pakistan Fertility Survey. Voorburg, Netherlands: International Statistical Institute. 1984.

4. Cochrane, S. Education and Fertility. What do We Really Know? Baltimore: Johns Hopkins University Press. 1979.

5. Irfan, M. "Studies in Population, Labour Force and Migration: A PIDE/ILOUNFPA Project". Islamabad: Pakistan Institute of Development Economics. 1981. (Research Report No. 118; Mimeographed)

6. Irfan, M., and I. Alam. "Fertility in Pakistan - A Fresh Evidence". 1984. (Mimeographed; available from the authors at PIDE, Islamabad, Pakistan)

7. Irfan, M., and G. Farooq. "An Investigation of Household Reproductive Behaviour in Pakistan". Islamabad: Pakistan Institute of Development Economics. 1983. (Studies in Population, Labour Force and Migration; Reprot No. 4)

8. Khan, Z. "Breast-feeding in Pakistan". 1983. (Mimeographed paper; available from the author at PIDE, Islamabad, Pakistan)

9. Mahmood, N., and Syed Mubashir Ali. "Nuptiality Patterns in Pakistan". Islamabad: Pakistan Institute of Development Economics. 1983. (Studies in Population, Labour Force and Migration; Report No. 2) 
10. Nizamuddin, M. "Community and Programme Variables and their Effects on the Fertility-Related Behaviour of Rural Pakistani Women". In Iqbal Alam and Betzy Dinesen (eds.), Fertility in Pakistan: A Review of Findings from the Pakistan Fertility Survey. Voorburg, Netherlands: International Statistical Institute. 1984.

11. Retherford, R., et al. “Fertility Estimates Based on Pakistan's 1979 Population Labour Force and Migration Survey”. 1983. (Mimeographed paper)

12. Sathar, Z. "Education and Fertility in Pakistan". Unpublished Ph.D. Thesis, University of London. 1982.

13. Soomro, G. Y., and Syed Mubashir Ali. "Prevalence of Knowledge and Use of Contraception in Pakistan". Islamabad: Pakistan Institute of Development Economics. 1983. (Studies in Population, Labour Force and Migration; Report No. 3) 


\section{Comments on}

\section{"Reproductive Behaviour in Pakistan: Insights from the}

\section{Population, Labour Force, and Migration Survey \\ 1979-80"'}

This is a difficult paper to discuss as it involves extensive work. The difficulty arises from the fact that it attempts to partly summarize a whole host of previous studies and as such there is a need for reference and cross references. What I should have liked to see was the authors' evaluation of the objective of the paper. If it is intended as a survey, then it does draw up several topics for discussion. However, the objective of surveying PLM results is somewhat premature and somewhat too broad, especially since the results are not fully out and further analysis is needed. In terms of pointing the way for further research, I think this paper is a very successful starting point and my comments will focus on that aspect.

Because it is a serious study I shall enter into quite a lot of detail, but in order to focus my discussion, let me just summarize the paper. It is in two parts. Part I is essentially a comparison with the results of the Pakistan Fertility Survey (1970-75) and basically a few themes have been thrown up. One is whether the 12-percent decline in fertility claimed by the PFS can be substantiated. The second presents multivariate analysis and coefficients of age at marriage, birth intervals and length of breast-feeding, and infant mortality. So Part I is basically a description of how those results can be substantiated or refuted or made inconsistent with this four-in-one venture of Migration, Fertility and so forth. Part II goes into statistics and details of a particular model to estimate the determinants of the children ever born.

So let me start with Part II, and I come specifically to one crucial sentence in the paper. (I am going to take this study as a serious study and a serious study has to be carefully looked at.) This sentence in the paper states "that attempts were also made in the regression analysis to incorporate as many of the variables from all four modules of the surveys that were thought to be pertinent to the fertility behaviour". So we have a very rich data source and it has information on fertility, migration, income and expenditure and labour force participation, and, of course, there is a lot of simultaneity involved and, of course, we have to try to include all possible relationships. But this sentence disturbs me because I would much rather have seen 
precise hypotheses sharply focused, and models brought to bed. And let me now continue in that vein, and remind you of that part that there are two options of proceeding with such an analysis. We either follow the Chicago demand-oriented model and consider certain sub-groups to see what determines the parents' desire for children. Why do they have children? The other approach is that of the supply side which is the Easterlin hypothesis. The supply side emphasizes the biological constraints of reproduction and the demand side emphasizes the behavioural elements. One, then, has to decide what are the objectives of Part II. If it is an attempt to describe the behavioural relationship or the biological relationships, then the best way of entering in this area, since it is a massive data source, is by keeping the basic benchmarks in mind. Using these basic benchmarks to proceed more into the paper, I would now particularly like to point out the regression results reported which form the heart of Part II of the study. There are results from regression analysis with children ever born to ever-married women, aged 15 to 50 years, as the dependent variable and selected demographic and socio-economic independent variables where a serious effort is being made to try to find out what influences fertility. What is fertility and what influences fertility? The answer to the first question is clear: children ever born to women aged 15 to 50 . So first I ask what is the nature of the dependent variable? Is this the correct way to formalise fertility and what are we trying to explain? If it is completed family then the choice of women aged 15-50 is obviously not appropriate. It also does not measure desired family size. The first question which I would like to ask and hopefully the authors will respond to is what is being measured by the dependent variable, viz. children ever born to women aged 15-50? Of course age is being controlled, and in a sense one could say, it is a measure of completed family size. But I would have preferred another filter (it is not in the best spirit to bring one's own work but it is also Professor Sirageldin's work and on that excuse, I can point out) as when we tried to get at completed family size, we took the age group $39-45$ and we then added a filter, based on the negative reply to the question: Do you want additional children or not? So we thus focused on a small sample which in a sense had greater justification as having completed their family size. $R^{2} s$ in that study were around (.2), i.e. 20 percent, whereas in this study, they are hovering around $50,53,58$ percent. Therefore, it is important to clarify what aspect of fertility you are trying to measure.

Secondly, what is the justification of splitting the population into four variables? We know that fertility in urban metropolitan areas is presumably different from that in rural areas, which is presumably different from that on rural farms, which is presumably different from that rural non-farms; but in an empirical exercise it would have been more efficient if these had been treated as dummies and tested for significance and one full sample with its fully efficiency properties was utilized. If the dummy was significant then a sub-classification may be more warranted. As a broad point, this sub-classification may be appropriate but I would have liked to see some justification for it. Thirdly, I think there is too speedy an entry into a presentation of regression results. Let us start with rough categories, for example, Dr. Sathar mentioned, tractor ownership, but what does tractor ownership measure. Is it really a proxy for income or is it proxy for well-being? Or, do you really believe that if a person buys a tractor, his fertility behaviour would go down. In a sense it is like a straw man and you can take the straw man out. In our study of the 1968 National Impact Survey, we did not even have income data, but one of the variables which we had was adequacy of income. It was a very rough measure and a very broad measure but it came out significant. The question arises: What are the policy prescriptions of such a finding? Since we have some idea of the basic thing which we are trying to get, whether any advancement on the economic scale is associated with increasing or decreasing fertility - the results did not answer this. That same ambiguity prevails in this paper too which I will point out later. Fourthly, there is something which is close to my heart for the reason that now I have spent a fair amount of time researching it, viz. son preference. The result presented in the paper is apparently interesting but again the question is: What does it mean? When the dependent variable is children ever born to women aged 15 to 50 , and son preference is measured by the number of daughters currently living divided by the number of children currently living, then the greater the proportion of daughters, the higher the number of children ever born. Does this finding really show that people really desire sons or is it simply a justification of a biological relationship? Knowing that the probabilities of having a child of either sex are 50 percent, those who have ten children, five of them, after allowing for mortality, would be daughters. I personally doubt that it is just a justification of biological relationship as regression after regression has shown very strong son preference in Pakistan. But indeed there is now a very good model for son preference which I will come back to later and would like to see as a next step for testing that model on these data.

Fifthly, the breast-feeding results are interesting but I was struck by their interpretation. The authors seem to argue that the length of breast-feeding is more an index of economic well-being and that the educated, the really well-to-do and the more modern are those who move over to non-breast-feeding. This raises two issues. One is, again, the preliminary nature of the analysis at this stage and therefore one ought to be cautious in being too precise; and secondly, its coefficient is inconsistent with the results on the effects of income and well-being on fertility. This needs to be looked into in somewhat more detail. Sixthly, the authors find nuclear families to be associated positively with fertility. What does this mean? If you really take the
nuclear family arrangements and talk in terms of women's time, presumably you

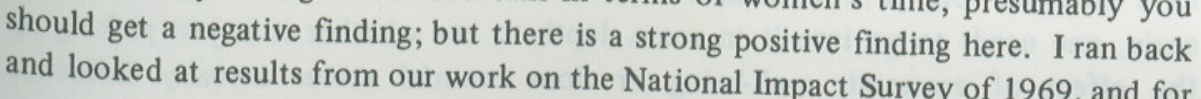


the rural sample you got a strong significant negative finding for nuclearization. It does not mean that we are necessarily right but it means that there is a lot of ambiguity in the meaning of nuclearization which needs to be studied. I think this is a unique venture in that here all the 3-4 modules have been pooled, but the variables included have to be evaluated to see what it is they are really measuring.

Having gone into detail on this, now let me give you some broad points. I would like to see more detail on specific aspects. I would like to see either a demand model with the desired number of children or the additional number of children desired and run that out with some basic rudimentary theory and see what these results look like and I think that would be an encouraging next step. I would like to report here that I am now at present involved in a similar study on Egypt and the findings were very encouraging in terms of the Chicago approach. Even though it is not really a highly developed society, but we are now focusing on their desired family size and not on what they actually achieved. So there are none of the problems of picking variables for which data have no reliance. You ask women how many children they want and their attributes and you relate the two as there is some theoretical justification for it. The other aspect I would like to see developed is a much more detailed study on birth intervals. There are a lot of possibilities of some very imaginative work here, parallel to the field of industrial organization, where you have a very natural way of pooling time-series and cross-section data. As an example, one runs profit rates in different time periods for different firms. So you have information over time and information for each firm but the profit rate pertaining to a particular firm has somehow more relevance to that firm than to others. The birth interval problem has similarities because you have women and you have their intervals. These intervals pertain much more directly to the women just as the profit rates pertain to a firm. So presumably the same sort of estimation method could be used and some not very fancy methods can be applied. You can start with measuring variations with ordinary Chi squares and so forth.

I found Part I of the paper very strong, relative to what it has set out to do. It is a descriptive exercise and there are no regressions but in terms of what it sets out to do no faults can be found. The age-at-marriage results are very interesting but again now the next step would be to use a model. One could refer to recent work on Kerala and Karnataka. One should also see those women who are not married as a test and see some estimates for them. The question of period of childbirth is another interesting finding but hopefully that will be substantiated and strengthened in the supply-side model, which I referred to earlier, with birth intervals. The infant mortality findings are very interesting and let me just go through three things which have emerged. One is the influence of land tenure and infant mortality. But now, again, one needs to go into it in some depth to see whether it is just picking up the effect of economic well-being or does tenurial status actually influence differences in infant mortality. In the same vein, landlessness or being a small farmer is associated with lower infant mortality and it is questionable whether that portrays a direct relationship or is it due to their strong association with income. This question I have nowhere seen posed in the paper and there are some findings on land tenure and infant mortality which should be checked up; e.g. the question of whether boy babies die quicker than girl babies and how much of a sex bias is there in infant mortality. This is potentially another interesting finding, as once you find a differential then the son preference variable used in the multivariate analysis would have more credence. The third thing which is of interest is the significance of the education of the father and the mother in determining infant mortality.

So, in broad terms, I think this is a very good conference paper. In a sense it shows all the work that has been done thus far. It shows also further possibilities, and they are immense not only in terms of techniques of studies etc.,but I would mention that there has been work on Pakistani fertility which should be seen and brought much more into the focus of the paper. I think it will not only add to the findings here but will also give insights for further work, especially in the more sensible interpretation of regression coefficients.

Professor,

Department of Economics,

M. Ali Khan University of Illinois,

Champagne, Ill. 